\title{
用差示扫描量热法研究水合醛缩酶中的 不冻结水与可冻结水
}

刘云娜谈夫

(中国科学院化学研究所, 北京)

最近的研究 ${ }^{[1-6)}$ 表明,蛋白质在水合过程中, 其吸收水可处于不同的状态. 其中一部分水 的分子与蛋白质分子表面的亲水部位以氢键相结合, 这部分水的分子不参加到冰的点阵中, 成 为不冻结的水 (也称结合水). 而另一部分水, 则是可以冻结的水, 但由于熔化焓和熔化温度不 同, 这部分水仍可处于不同的状态. 在差示扫描量热法的研究中有关蛋白质中可冻结水与不 冻结水量的计算, 文献中采用的方法通常是用总的熔化烚除以纯冰的熔化焓来得到可冰结水 的量,再从总的水含量中减去可冻结水的量, 以求得不冻结水的量 ${ }^{[7,8]}$. 我们的实验表明, 当水 含量升高至某一值以上时, 每克可冻结水的熔化焓基本上与每克纯冰的相同, 可以用上述方法 来计算. 但在水含量低于该值时, 由于水的状态不同, 每克可冻结水的熔化焓要比每克纯冰的 低很多,此时再用上述方法计算就会引起很大的误差. 鉴于这种情况, 我们在计算方法上做了 改进,计算出不同水含量时,不冻结水和可冻结水的量.

兔肌䤊缩酶是具有四个亚基的四聚体酶, 也是生物体内的一种重要的血清酶. 有关水合 醀缩酶中吸收水的状态以及不冻结水与可冻结水量的研究, 未见文献报道.

\section{一、实验与数据处理}

试样兔肌醴缩酶, 粉末状结晶, 中国科学院上海生化所东风生化试剂厂产品, 活力>5 $\mathrm{u} / \mathrm{mg}$, 分子量为 158000 .

水合酲缩酶样品的制备 将粉末状的醀缩酶置于样品盘内称重, 加入适量 的重蒸馏 水, 然后加盖, 用密封器密封, 称重, 在室温下平衡 5 天待测. 试样用 $\mathrm{P} / \mathrm{EAD}-2 \mathrm{Z}$ 型超微量 电磁天平称量. 每次试样用量: 醛缩酶样品约为 $1.69 \mathrm{mg}-2.44 \mathrm{mg}$, 加入水量约为 $0.15 \mathrm{mg}-$ $4.64 \mathrm{mg}$.

仪器与实验 使用 $\mathrm{P} / \mathrm{E}$ DSC-2C 型差示扫描量热计, 测量冻结的水合醛缩酶样品中吸 收水的总熔化焓和熔化温度. 仪器配以低温装置、3500 数据站及 HP $7225 \mathrm{~A}$ 型绘图仪. 用 高纯铟和环已烷 (色谱标准) 对仪器的温度和能量进行标定. 量热测定的准确度约为 $\pm 1 \%$. 仪 器灵敏度为 $8.3735 \times 10^{-3} \mathrm{~J} / \mathrm{s} \cdot$ 满刻度, 升温速率为 $10^{\circ} \mathrm{C} / \mathrm{min}$, 样品盘和参考盘使用挥发型铝 盘, 温度扫描的范围为 $-40-20^{\circ} \mathrm{C}$. 将待测的水合醛缩酶样品置于 $-40^{\circ} \mathrm{C}$ 保持 $10 \mathrm{~min}$, 然后 进行测量.

水含吾 $h$ 的计算 实验结束后, 在样品盘的盖上扎数个小孔, 置于 $110^{\circ} \mathrm{C}$ 下烘干至恒

本文 1986 年 3 月, 5 日收到.

第 1 期

科学 通报 
重, 然后进行重量分析, 根据干蝠前后失重的量和蛋白的量来计算水含量 $h . h$ 的单位为: $\mathrm{g}$ 水 $/ \mathrm{g}$ 蛋白.

数据处理 用实验测得的水合醛缩酶中可冻结水的总的熔化焓 $\Delta H_{\mathrm{g}}$ 对水含量 $h$ 作图， 结果如图 1 所示. 运用线性回归法对实验点进行处理, 得到两条直线, 其交点约在 $h=0.95$ 处. 在 $h>0.95$ 时, 得到的线性方程为

$$
\Delta H_{\mathrm{a}}=80.7 h-29.4 \text { (相关系数 } r=0.999 \text { ), }
$$

在 $h<0.95$ 时, 得到的线性方程为

$$
\Delta H_{\text {省 }}=64.8 \mathrm{~h}-14.3 \text { (相关系数 } r=0.997 \text { ), }
$$

两条直线的斜率分别为 80.7 和 64.8. 斜率表示水合醛缩酶中每克可冻结水的熔化焓 (Cal/ $\left.\mathrm{gH}_{2} \mathrm{O}\right)$. 若熔化焓的单位采用焦耳 (J), 则, 在 $h>0.95$ 时, 每克可冻结水的熔化焓为 337.3 $\mathrm{J}$, 这和每克纯冰的熔化焓 $333.6 \mathrm{~J}$ 是相当的, 因此, 可冻结水和不冻结水的量可按通常的计算 方法得到. 但在 $h<0.95$ 时,每克可冻结水的熔化焓为 $270.9 \mathrm{~J}$, 显然,此时可冻结水的状态与 纯水相差甚远，计算可冻结水和不冻结水的量不宜采用前面提到的通常的计算方法. 而应该 是将总的熔化焓 $\left(\mathrm{J} / \mathrm{g}\right.$ 蛋白)除以 $270.9 \mathrm{~J} / \mathrm{gH}_{2} \mathrm{O}$, 以求得可冻结水的量, 然后再从总的水含量中 减去可冻结水的量,以求得不冻结水的量.

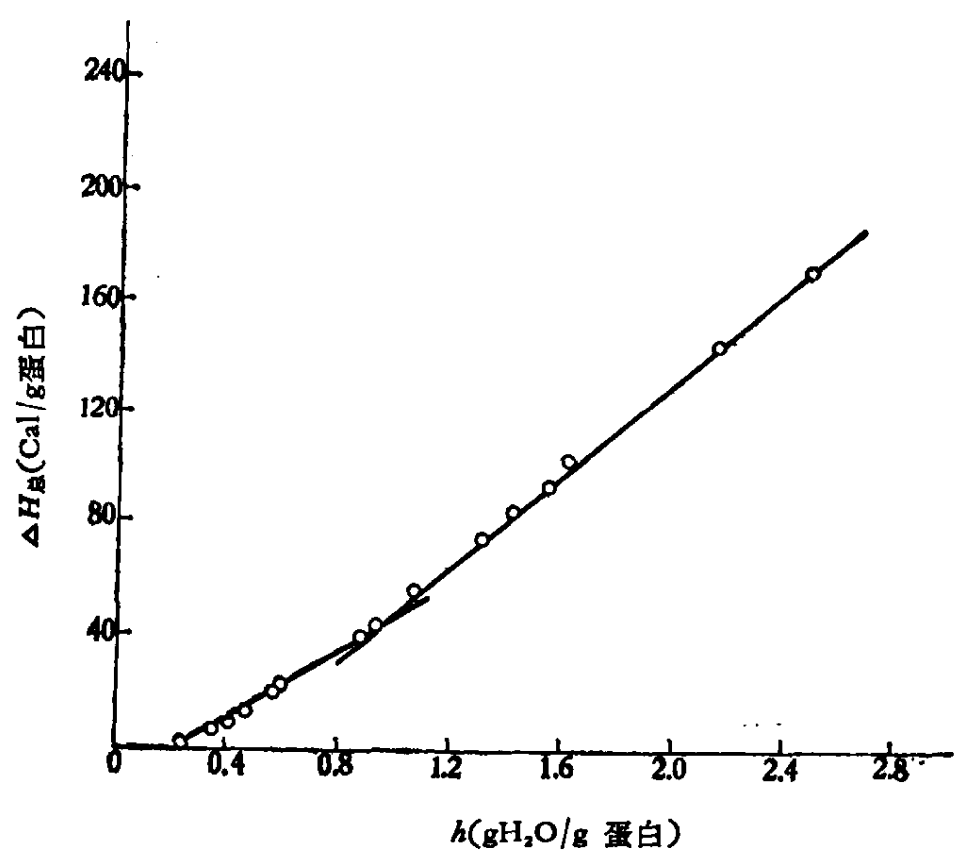

图 1 冻结的水合醮缩酶中可冻结水的总的熔化焓与水含量的关系

\section{二、结果与讨论}

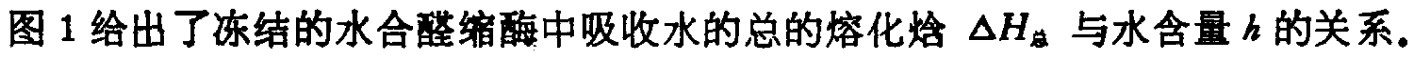

表 1 列出了按上述计算方法得到的不同水含量时水合酩缩酶中可冻结水与不冻结水的 量,用每克蛋白中含水的克数表示(即 $\mathrm{gH}_{2} \mathrm{O} / \mathrm{g}$ 蛋白).

由表 1 可以看出, 当水含量 $h \leqslant 0.35$ 时, 水合醛缩酶中不冻结水的量是随着水含量的增 加而增加,当 $0.35 \leqslant h<0.95$ 时, 不冻结水的量稳定在 0.25 左右, 当水含量高于约 0.95 时, 不 冻结水量增至 0.36 左右, 并且随水含量的增加不再变化. 不冻结水量由 0.25 增至 0.36 的变 化, 可能是由于当水含量增加到约为 0.95 这一值时, 蛋白质的构象会产生一个小的突变并达 
表 1 不同水含量的水合醛缩酶中可冻结水与不冻结水的墨

\begin{tabular}{c|c|c}
\hline 水含曼 $\left(\mathrm{g} \mathrm{H}_{2} \mathrm{O} / \mathrm{g}\right.$ 蛋白 $)$ & 可冻结水 $\left(\mathrm{gH}_{2} \mathrm{O} / \mathrm{g}\right.$ 蛋白 $)$ & 不冻结水 $\left(\mathrm{gH}_{2} \mathrm{O} / \mathrm{g}\right.$ 蛋白 $)$ \\
\hline 0.08 & 0 & 0.08 \\
0.23 & 0.03 & 0.20 \\
0.35 & 0.10 & 0.25 \\
0.41 & 0.15 & 0.26 \\
0.47 & 0.21 & 0.26 \\
0.57 & 0.31 & 0.26 \\
0.59 & 0.35 & 0.24 \\
0.88 & 0.63 & 0.25 \\
0.93 & 0.69 & 0.24 \\
1.07 & 0.71 & 0.36 \\
1.31 & 0.95 & 0.36 \\
1.42 & 1.06 & 0.36 \\
1.55 & 1.18 & 0.37 \\
1.62 & 1.27 & 0.35 \\
2.15 & 1.80 & 0.36 \\
2.40 & 2.03 & 0.37 \\
2.50 & 2.13 & 0.37 \\
\hline
\end{tabular}

到另一个稳定构象所致. 从表 1 还可以看出, 当 $h<0.23$ 时,没有可测量的可冻结水的熔化 蜂, 说明此时水合醛缩酶中全部吸收水为不冻结水, 在 $h \geqslant 0.23$ 时, 测量到可冻结水的熔化 峰, 而且可冻结水的量是随着水含量的增加而增加. 每种蛋白质因其分子量和表面极性基团 的数量不同,因而都有自己特征的不冻结水量. 蛋白质的这一特性, 可用来作为蛋白质是否变 性和蛋白食品保存的质量好坏的一项检测指标。

由图 1 可以看出, $\Delta H_{\text {品 }}-h$ 关系图,不是一条直线,不能用同一个线性方程来描述它,也 就是说, 在所测量的整个水含量范围内, 可冻结水的量不能简单地用 $\Delta H_{\text {。 }}$ 除以纯水的熔化焓 来得到. 本工作中采用前面提到的两个焓值的处理方法, 计算出水合醛缩酶中可冻结水与不 冻结水的量. 这样处理, 较之文献的方法更为合理、更接近实际情况. 这是因为由于蛋白质和 水的相互作用,使蛋白质中的水处于不同的状态, 在低水含量 (对水合酫缩酶, 大约在 $h<0.95$ ) 时,蛋白质中可冻结水的熔化焓明显地低于纯冰的熔化焓. 运用回归分析得到的两个焓值, 更 准确地说, 是在一定水含量范围内存在着的不同状态的可冻结水的熔化焓的平均值,但这并不 影响计算可冻结水的量以及由此得到的不冻结水的量.

[1] Haly, A. R. and Snaith, J. W., Biopolymers, 7(1969), 459-474.

[2] Haly, A. R. and Snaith, J. W., Biopolymers, 10(1971), 1681-1699.

[3] Berlin, E. et al., J. Coll. Interf. Sci., 34(1970), 488-494.

[4] Hansen, J. R., J. Agric. Food Chem, 24(1976), 1136-1141.

[5] Hansen, J. R., J. Agric. Food Chem., 26(1978), 301.

[6] Cecorulli, G. et al., Biopolymers, 16(1977), 1505-1512.

[7] Ross, K. D., J. Food Sci., 43(1978), 1812-1815.

[ 8 ] Röegg, M. et al., J. Dairy Sci, 59(1974), 387-393. 